\title{
Physics Lessons from the World of Music
}

\author{
Stephon Alexander draws on his background in music and his interactions \\ with jazz performers to help him "compose" physics models in string \\ theory.
}

By Katherine Wright

$\square$ tephon Alexander is not your ordinary physicist. Well known in physics circles for his work on a string-theory-based model of the early Universe, Alexander, currently at Brown University in Rhode Island, is equally as famous in the jazz scene for his saxophone playing. He collaborated with the producer Erin Rioux on an album called "Here Comes Now," and he plays with guitarist Melvin Gibbs in a group called God Particle, which performed at last year's Vision Festival in New York. In a recent talk at the 2020 National Society of Black Physicists (NSBP) conference (see Building Community Among Black Physicists), Alexander acknowledged the role music has had in his physics successes. He encouraged listeners to embrace the arts and their

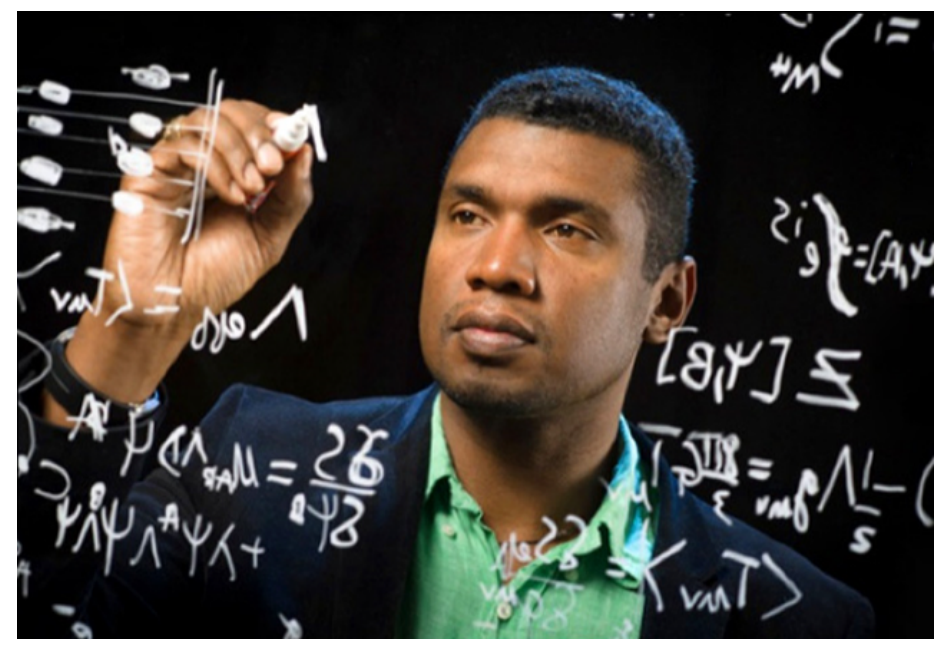

String theorist Stephon Alexander balances a dual life in music and physics.

Credit: S. Alexander alternative ways of thinking, an approach that has given him the courage to tackle big physics problems.

For Alexander, music and physics have always been intertwined. Raised in a musical family, he started playing saxophone at a young age, but his interest in learning how to produce different notes and timbres was matched by his desire to understand why his instrument made those varied sounds. But it wasn't until high school, when Alexander came across Feynman's autobiography Surely You're Joking, Mr. Feynman! that he got hooked on the idea of being a physicist.

Intrigued by Feynman's prose, Alexander started delving into other books and papers on the murky world of quantum theory. He was fascinated by the spooky particles that could simultaneously be in multiple places, and he slowly became more convinced that quantum mechanics-or physics generally-was really for him. "The equations were daunting," he said. "I didn't know that I had what it would take to be a physicist." Luckily for physics, music showed him the way. Alexander realized that he could use techniques that he had developed to remember musical chords to help interpret equations, visualizing them as pictures instead of strings of mathematical symbols. Feynman is famous for doing something similar, using wiggles and loops to encode the mathematics of subatomic particles. Discovering that "lifehack," Alexander said, gave him the confidence to continue his journey into science research.

Another music-related takeaway that helped Alexander in his science career came from one of his friends, Brian Eno. Eno is 
celebrated as the father of so-called ambient music, which is an electronic, soft-sounding music that is often heard in airport lounges. According to Alexander, Eno came up with the idea for ambient music while he was in the hospital, showing that musical inspiration could come from anywhere. Applying this lesson to his physics career, Alexander has often gone to jazz venues and night clubs to work on his physics theories. "I deliberately placed myself in a different environment," he said. "I don't think I would have done that without the inspiration from Brian." The move gave him space to think outside of the box and to riff on new ideas-such as a link between string theory and cosmology.

Keeping an open mind to different ways of doing something is a point Alexander emphasized throughout his talk. That openness has given him freedom to embrace quirky ideas-even if some of them led him down the wrong path. For example, in 2007, the physicist proposed that dark matter could be a network of cosmic strings that formed after a rapid expansion phase in the early Universe called inflation. His theory correctly predicts the motions of galaxies, but it incorrectly predicts the behaviors of gravitational lenses. But Alexander doesn't see the work as a failure. Teasing out where a theory misses the mark is just as important for understanding a problem as knowing when it fits, he said. He notes that his cosmic-string idea has found life in the art world, inspiring a sculpture by Ned Kahn. "Cosmic strings have had an impact, just not in the way I thought," he said.

Alexander encourages his fellow physicists to be open to nontraditional paths and to the possibility of failure-to be unafraid to hit a false note. "Being wrong can take you in a direction that you never thought to go in, and sometimes that direction bears unexpected fruit that you never would have seen if you were right."

Katherine Wright is a Senior Editor for Physics. 